12

\title{
Электрический взрыв проводника \\ в энергоаккумулирующих фазовых материалах с наноразмерными полупроводящими добавками
}

\author{
(ㄷ Г.Г. Савенков ${ }^{1}$, В.А. Морозов ${ }^{2}$, А.А. Лукин ${ }^{2}$
}

${ }^{1}$ Санкт-Петербургский государственный технологический институт (технический университет)

${ }^{2}$ Санкт-Петербургский государственный университет

E-mail: sav-georgij@yandex.ru

\section{Поступило в Редакцию 20 мая 2016 г.}

\begin{abstract}
Представлены результаты экспериментов по взрыву медного проводника в парафине и воске как без добавок, так и с наноразмерными добавками окиси меди. Эксперименты позволили получить значение размеров канала, образующегося в образцах из воска, при взрыве проводника и последующего расширения электроразрядной плазмы. Полученные результаты свидетельствуют о влиянии наноразмерных добавок на характер процесса расширения электроразрядной плазмы в образующемся канале, на прочность композиционных материалов и на процесс фрагментации (разрушения) образцов.
\end{abstract}

В настоящее время в аэрокосмической промышленности все большее применение находят так называемые тепловые композиты на основе комбинации энергоаккумулирующих фазовых материалов (материалы с изменением фазы — phase change material (PCM)) и материалов с высокими значениями теплопроводности. Прочностные свойства таких композитов в экстремальных условиях нагрузок (миллимикросекундной длительности) и температур, которые свойственны для аэрокосмической техники, практически не изучены. В этом плане электрический взрыв проводника (ЭВП) в тепловом композите представляется одним из перспективных электрофизических методов, который позволит получить некоторые данные о поведении данного класса материалов при действии нагрузок и температур микросекундной длительности. Кроме того, исследование влияния характеристик среды, в которой происходит 


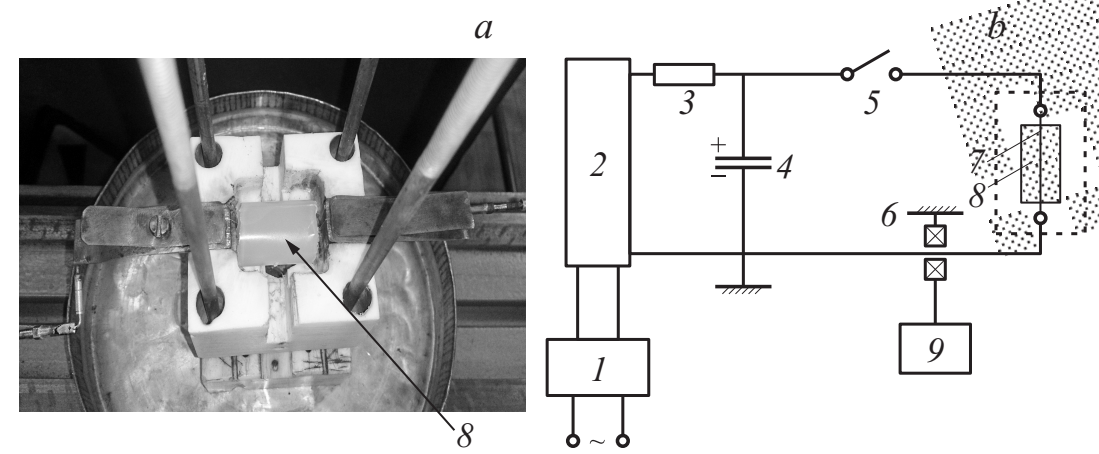

Рис. 1. Внешний вид образца $(a)$ и схема экспериментальной установки $(b)$ : 1 - автотрансформатор; 2 - выпрямитель; 3 - зарядное сопротивление; 4 - конденсатор; 5 - разрядник; 6 - пояс Роговского (измеритель тока); 7 - взрываемый проводник; 8 - образец из фазового материала; пунктиром показан защитный кожух.

электрический взрыв проводника, на параметры процесса ЭВП является не менее актуальной задачей, чем вышеуказанная проблема.

Простейшими тепловыми композитами являются композиты на основе медной сетки, погруженной в парафин или воск. В настоящей же работе вместо медной сетки использовался наноразмерный $(\sim 100 \mathrm{~nm})$ порошок окиси меди, который перемешивался с парафином или воском. Кроме всего прочего, ожидалось, что применение наноразмерных компонентов позволит получить принципиально новые свойства исследуемых материалов (парафина, воска).

Таким образом, задачами данной работы являлись: 1) изучение динамических свойств тепловых композитов на основе парафина и воска с добавлением наноразмерного порошка окиси меди и 2) оценка влияния характеристик среды, в которой происходит электрический взрыв проводника, на параметры процесса ЭВП.

Путем плавления и перемешивания в разборных контейнерах диаметром $20 \mathrm{~mm}$ и высотой $25-30 \mathrm{~mm}$, в которых уже находилась закрепленная по центральной оси медная проволочка диаметром 75-80 $\mu \mathrm{m}$ и длиной $100 \mathrm{~mm}$, изготавливались цилиндрические образцы различной плотности и процентного содержания порошка.

Письма в ЖТФ, 2016, том 42, вып. 22 
Параметры образцов и процесса ЭВП

\begin{tabular}{c|c|c|c|c|c|c}
\hline № & $\begin{array}{c}\text { Материал } \\
\text { матрицы }\end{array}$ & $\begin{array}{c}\text { Массовая } \\
\text { доля } \\
\text { порошка, } \\
\%\end{array}$ & $\begin{array}{c}\text { Масса } \\
\text { образца, } \\
\mathrm{g}\end{array}$ & $\begin{array}{c}t_{1}, \\
\mu \mathrm{s}\end{array}$ & $\begin{array}{c}t_{2}, \\
\mu \mathrm{s}\end{array}$ & $\begin{array}{c}t_{3}, \\
\mu \mathrm{s}\end{array}$ \\
\hline 0 & Воздух & 0 & - & 1.0 & 1.75 & 14.0 \\
1 & Парафин & 0 & 4.21 & 1.25 & 2.75 & 7.0 \\
2 & Парафин & 0 & 7.330 & 1.25 & 2.75 & 9.0 \\
3 & Парафин & 5.8 & 7.355 & 1.5 & 2.75 & 11.5 \\
4 & Парафин & 7.3 & 4.360 & 0.75 & 2.75 & 11.5 \\
5 & Воск & 0 & 4.80 & 1.0 & 2.25 & 10.5 \\
6 & Воск & 0 & 6.50 & 1.0 & 2.25 & 12.0 \\
7 & Воск & 4.9 & 6.61 & 0.75 & 2.25 & 12.5
\end{tabular}

Примечания: $t_{1}$ - время до взрыва проводника; $t_{2}$ - время до первого максимума на синусоиде тока после взрыва проводника; $t_{3}$ - общее время процесса.

Данные по образцам и результаты экспериментов приведены в таблице. Нулевой эксперимент обозначает электрический взрыв медного проводника на воздухе. На рис. 1 приведены внешний вид образца $(a)$, установленного в экспериментальной установке, и электрическая схема эксперимента $(b)$.

Разрядное напряжение во всех экспериментах составляло $20 \mathrm{kV}$, емкость конденсатора $0.5 \mu \mathrm{F}$. За момент времени $\left(t_{1}\right)$ взрыва проводника принимали момент резкого изменения характера кривой напряжения тока на фиксируемой осциллограмме. В таблице также приведены значения времени до первого максимума на синусоиде тока после взрыва проводника $t_{2}$.

Время $t_{2}$ выбрано нами из тех соображений, что оно характеризует процесс прохождения тока после взрыва проводника, когда его материал находится в смешанном состоянии жидкого металла с включениями металлических паров. Такое состояние материала сильнейшим образом влияет на электрические свойства (например, проводимость) канала и соответственно на значение тока. И, наконец, это состояние наименее изучено с точки зрения изменения электропроводности металлов и влияния на него различных факторов [1].

Письма в ЖТФ, 2016, том 42, вып. 22 


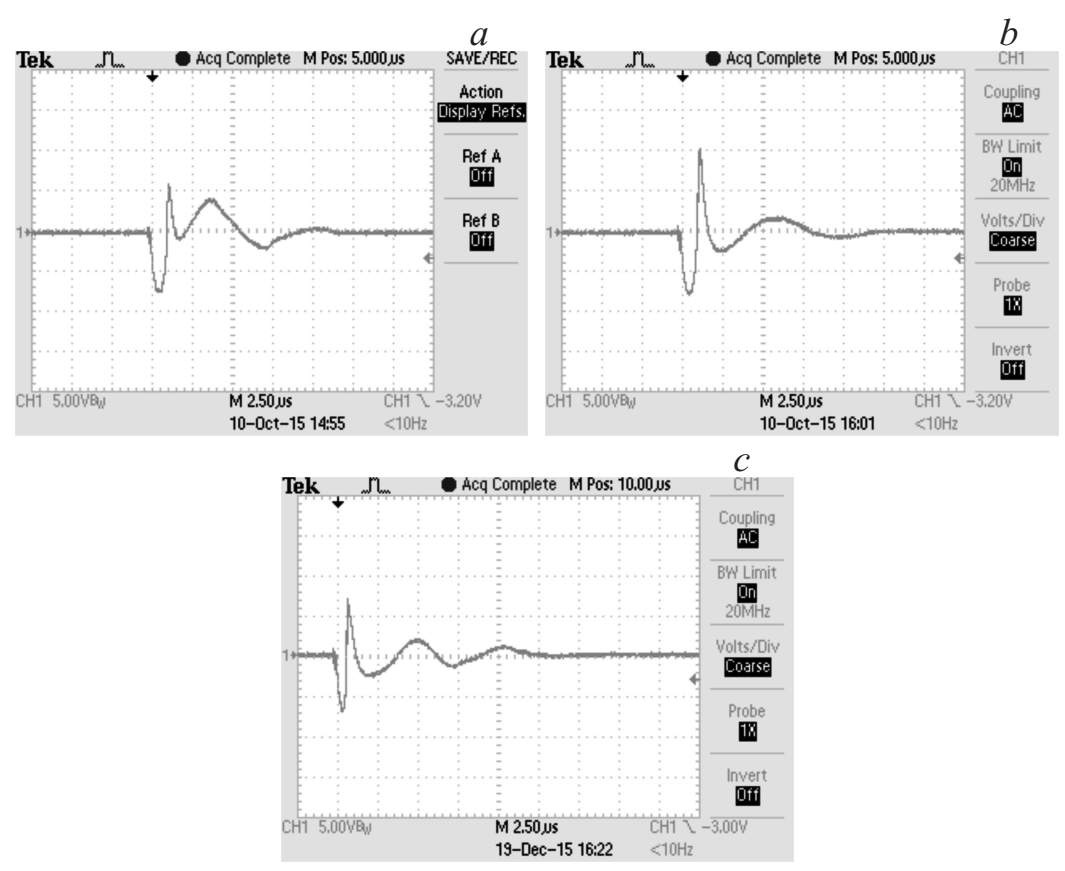

Рис. 2. Осциллограммы тока электрического взрыва проводника.

На рис. 2 приведены осциллограммы: $a-$ ЭВП на воздухе, $b-$ тока электрического взрыва проводника в парафине с 7.3\% массовой доли $\mathrm{CuO}, \mathrm{c}$ - тока ЭВП в воске с $4.9 \% \mathrm{CuO}$.

Прежде чем переходить к анализу результатов экспериментов, приведем значения теплопроводности $\lambda(\mathrm{W} / \mathrm{m} \cdot \mathrm{K})$ и удельной проводимости материалов $\rho(\Omega \cdot \mathrm{m})$ : для воздуха $\lambda=0.025, \rho=10^{15}-10^{18}$ (значения удельной проводимости приведены для $0^{\circ} \mathrm{C}$ ); для парафина $\lambda=0.268, \rho=10^{14}-10^{16}$; для воска $\lambda=0.101, \rho=10^{11}-10^{12}$ (для воска и парафина значения параметров приведены для комнатной температуры).

Анализ результатов, приведенных в таблице, показал, что материалы образцов (включая воздух), в которых находится проводник, по-разному влияют на процесс ЭВП. Время до взрыва проводника для всех трех

Письма в ЖТФ, 2016, том 42, вып. 22 
типов материалов приблизительно одинаковое и находится в диапазоне от 0.75 до $1.5 \mu \mathrm{s}$. Время до первого максимума на синусоиде тока четко различается: наименьшее время $(1.75 \mu \mathrm{s})$ при взрыве проводника на воздухе, наибольшее $(2.75 \mu \mathrm{s})$ - при взрыве проводника в парафине и промежуточное $(2.25 \mu \mathrm{s})$ время при взрыве проводника в воске. При этом время до взрыва в образцах из парафина или воска не зависит от наличия добавки $\mathrm{CuO}$. В данном случае время $t_{2}$ коррелирует с теплопроводностью материалов, окружающих проводник: чем меньше теплопроводность, тем меньше время до первого максимума на синусоиде тока.

Общее время процесса ЭВП также коррелирует с теплопроводностью: чем меньше $\lambda$, тем больше время процесса, т.е. полное время существования проводящей структуры (проволочка-плазма) связано с интенсивностью отвода тепла после испарения материала в окружающую среду: чем выше интенсивность, тем меньше время процесса. И этот фактор является превалирующим по отношению к плотности среды (поскольку известно, что повышение плотности затягивает процесс разрушения). Взаимосвязь между массой образца и временами $t_{i}$ отсутствует.

Примечателен характер разрушения образцов при ЭВП. Образцы из парафина, независимо от наличия полупроводящей добавки, разрушались на очень мелкие фрагменты, которые, в принципе, не удалось идентифицировать. Такое поведение образцов указывает на высокую хрупкость парафина при действии импульсного давления продуктов ЭВП и на существенное превышение значения этого давления порога хрупкой прочности материала.

Образцы из воска без порошковой добавки разрушаются на две половины (рис. $3, a$ ), образцы с добавкой 4.9\% разрушаются на 5-7 крупных фрагментов и достаточно большое количество мелких (рис. $3, b)$. И, наконец, образцы с добавкой $10.6 \%$ разрушаются на 25-26 крупных и средних фрагментов (рис. 3,c) и на мелкие фрагменты, которые уже не удается идентифицировать. При этом в первом случае диаметр канала, образованного продуктами ЭВП, составляет $1.5-1.7 \mathrm{~mm}$, во втором $\sim 3.0 \mathrm{~mm}$ и в третьем - $\sim 4.0 \mathrm{~mm}$.

Можно провести оценку давления от продуктов ЭВП в статическом приближении и без учета температуры по соотношению, полученному для расчета прочности толстостенной трубы на основе теории наибольших деформаций [2], адаптированному к нашему случаю нагружения

Письма в ЖТФ, 2016, том 42, вып. 22 

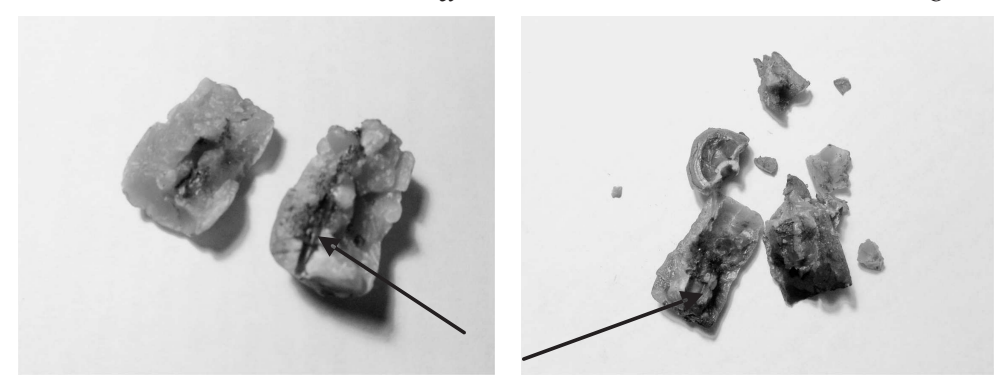

$c$

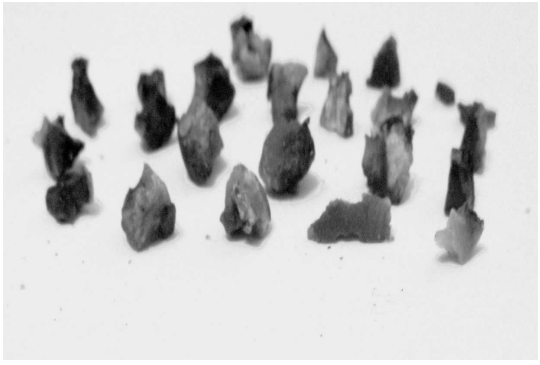

Рис. 3. Фрагменты образцов после ЭВП (стрелки указывают на канал, образованный продуктами ЭВП).

образца внутренним давлением:

$$
p_{1}=\frac{E \frac{\Delta r}{r_{1}}\left(a_{21}^{2}-1\right)}{(1-v)\left(\frac{1+v}{1-v} a_{21}^{2}+1\right)} .
$$

Здесь $p_{1}$ - искомое давление продуктов ЭВП, $r_{1}-$ начальный радиус внутреннего канала (радиус проводника $40 \mu \mathrm{m}), \Delta r=760 \mu \mathrm{m}$ - изменение радиуса вследствие нагружения образца, $E$ - модуль упругости материала образца (воска), $a_{21}=r_{2} / r_{1}=500-$ отношение наружного радиуса образца $\left(r_{2}\right)$ к внутреннему, $v-$ коэффициент Пуассона материала образца. Такая оценка дает следующее значение (единицей в числителе и знаменателе пренебрегаем, коэффициент Пуассона условно принимаем $v=0.36) p_{1} \approx 14 E$. Данные по модулю упругости воска 
отсутствуют (как, впрочем, и по модулю сдвига [3]), но можно предположить, что его порядок близок к $10 \mathrm{MPa}$ (данная оценка основывается на значениях модулей упругости каучука и резины). Тогда давление продуктов электрического взрыва медного проводника в соответствии с зависимостью (1) в образце из воска $p_{1} \approx 140 \mathrm{MPa}$.

Оценим давление в канале образца с привлечением ударно-волновых представлений. Используем для этого уравнение состояния в форме Ми-Грюнайзена, тогда максимальное давление в области электрического взрыва проводника (в предположении постоянства коэффициента Грюнайзена и удельной теплоемкости материала образца) определяется по соотношению (2)

$$
p_{\max }=\gamma \frac{E_{1}}{V},
$$

где $\gamma-$ коэффициент Грюнайзена воска; $E_{1}=\alpha E_{f}-$ энергия, вложенная во взрыв проводника; $E_{f}-$ энергия, запасенная на емкостном накопителе энергии; $\alpha<1-$ коэффициент преобразования электрической энергии в механическую работу; $V$ - объем канала. Примем $\gamma \approx 1.2-1.3$ [4] (отметим, что данное значение коэффициента близко к значениям $\gamma$ для наиболее распространенных взрывчатых веществ, а парафины являются исходным сырьем для ряда взрывчатых веществ и компонентов твердого ракетного топлива [5]), тогда в условиях эксперимента $(c=0.5 \mu \mathrm{F}, U=20 \mathrm{kV})$ при $\alpha=0.06-0.08$ [6] и длине канала $30 \mathrm{~mm}$ максимальное давление продуктов взрыва проводника лежит в диапазоне $p_{\max }=120-175 \mathrm{MPa}$. Полученное значение вполне согласуется с квазистатическим значением максимального давления (см. выше).

В случае образцов с наноразмерной добавкой $\mathrm{CuO}$, предполагая, что давление продуктов ЭВП не изменилось, а изменение коэффициента Пуассона мало, получим значение модуля упругости композита воск $+4.9 \% \mathrm{CuO} \quad E_{1} \approx E \frac{\Delta r}{\Delta r_{1}} \approx 0.52 E \quad\left(\Delta r_{1}=1.46 \mathrm{~mm}-\right.$ изменение внутреннего радиуса образца в образце с $\mathrm{CuO}$ ). Значение модуля упругости композита воск $+10.6 \% \mathrm{CuO}-E_{1} \approx E \frac{\Delta r}{\Delta r_{2}} \approx 0.39 E$ $\left(\Delta r_{2}=1.96 \mathrm{~mm}\right.$ - изменение внутреннего радиуса образца в образце c $\mathrm{CuO}$ ). Естественно, что приведенные оценки являются достаточно грубыми и годятся только для качественных сравнений. Тем не менее данные оценки весьма показательны.

Исходя из количества фрагментов, на которые разрушались образцы, можно было предположить, что наноразмерные частицы $\mathrm{CuO}$ в данном

Письма в ЖТФ, 2016, том 42, вып. 22 
случае не обладают упрочняющими свойствами, как этого следовало ожидать из анализа, проведенного в [7]. Вероятно, в большей степени эти частицы создают вокруг себя некие поля внутренних напряжений, которые не релаксируют со временем, превращаясь, по сути, в остаточные напряжения растяжения. Тогда области остаточных растягивающих напряжений вокруг частиц (а размеры этих областей, вероятно, уже могут превосходить наноразмеры) являются макроконцентраторами напряжений, т. е. некими „затравочными“ центрами областей механического разрушения образца, что делает их более хрупкими по отношению к образцам из чистого воска.

Вышеприведенные оценки значений модулей упругости только подтвердили данное предположение. На охрупчивание парафина при введении в него наноразмерных добавок $\mathrm{CuO}$ косвенно указывает достаточно резкое увеличение общего времени процесса ЭВП в образце с 7.3\% долей частиц $\mathrm{CuO}$.

На основании полученных экспериментальных результатов можно сделать следующие выводы:

1. Влияние энергоаккумулирующих фазовых материалов (парафина и воска) на процесс электрического взрыва проводника различно.

2. Давление продуктов электрического взрыва проводника в плазменном канале, образующемся в образце при ЭВП, может достигать сотен мегапаскалей.

3. Добавка в исследованные материалы наноразмерных частиц $\mathrm{CuO}$ приводит к общему охрупчиванию образцов.

\section{Список литературы}

[1] Синтез наноразмерных материалов при воздействии мощных потоков энергии на вещество / А.В. Булгаков, Н.М. Булгакова, И.М. Бураков и др. Новосибирск: Ин-т теплофизики СО РАН, 2009.

[2] Орлов Б.В., Ларман Э.К., Маликов В.Г. Устройство и проектирование артиллерийских стволов. М.: Машиностроение, 1976.

[3] Sabau A.S. // Investing Casting Institute 52-nd Technical Meeting. 2004. P. 1-11.

[4] Беломестных В.Н. // Письма в ЖТФ. 2004. Т. 30. В. 3. С. 14-19.

[5] Добрынин А.А. Взрывчатые вещества. Химия. Составы. Безопасность. М.: ИД Академии Жуковского, 2014.

[6] Лукин А.А., Морозов В.А., Судьенков Ю.В. // Вестник СПбГУ. Сер. 1. 2008. B. 2. C. $133-140$.

[7] Панин В.Е., Дерюгин Е.Е., Кульков С.Н. // ПМТФ. 2010. Т. 51. № 4. C. $127-142$. 